\title{
Burkholderia cenocepacia zinc metalloproteases influence resistance to antimicrobial peptides
}

\author{
Cora Kooi and Pamela A. Sokol
}

\begin{abstract}
Correspondence
Pamela A. Sokol

psokol@ucalgary.ca
\end{abstract}

Received 8 March 2009

Revised 5 June 2009

Accepted 11 June 2009

\author{
Department of Microbiology and Infectious Diseases, University of Calgary, Calgary AB T2N 4N1, \\ Canada
}

\begin{abstract}
Burkholderia cenocepacia secretes two zinc-dependent metalloproteases, designated ZmpA and ZmpB. Previously, ZmpA and ZmpB have been shown to cleave several proteins important in host defence. In this study, the ability of $Z \mathrm{mpA}$ and $\mathrm{ZmpB}$ to digest and inactivate antimicrobial peptides involved in innate immunity was examined. ZmpB but not $Z \mathrm{mpA}$ cleaved $\beta$-defensin- 1 . ZmpA but not ZmpB cleaved the cathelicidin LL-37. Both enzymes cleaved elafin and secretory leukocyte inhibitor, which are antimicrobial peptides as well as neutrophil elastase inhibitors. Both ZmpA and ZmpB cleaved protamine, a fish antimicrobial peptide, and a $z m p A z m p B$ mutant was more sensitive to protamine killing than the parental strain. $Z m p A$ or $Z m p B$ cleavage of elafin inactivated its anti-protease activity. The effect of $Z \mathrm{mpA}$ and $Z \mathrm{mpB}$ on the neutrophil proteases elastase and cathepsin $G$ was also examined but neither enzyme was active against these host proteases. These studies suggest that $\mathrm{ZmpA}$ and $\mathrm{ZmpB}$ may influence the resistance of $B$. cenocepacia to host antimicrobial peptides as well as alter the host protease/anti-protease balance in chronic respiratory infections.
\end{abstract}

\section{INTRODUCTION}

The Burkholderia cepacia complex (Bcc) consists of at least 17 different species based on 16S RNA sequences, DNADNA homology, lipid and fatty acid analysis and phenotypic characteristics (Coenye et al., 2001, 2003; Vandamme et al., 1997; Vanlaere et al., 2008, 2009). The $\mathrm{Bcc}$ are important pathogens in people with cystic fibrosis (CF) as well as emerging opportunistic pathogens in nonCF patients (Govan et al., 2007; Mahenthiralingam et al., 2005, 2008). Some Bcc strains are transmitted between patients and have been referred to as epidemic strains (Chen et al., 2001; Coenye \& LiPuma, 2003; Govan et al., 1993; LiPuma et al., 1990; Speert et al., 2002). Although strict infection control measures have reduced Bcc infections to only $4-7 \%$ of CF patients (Govan et al., 2007; Mahenthiralingam et al., 2005), these infections can result in necrotizing pneumonia and sepsis that can lead to the rapid deterioration of the patient in what has been termed 'cepacia syndrome' (Isles et al., 1984). In patients without 'cepacia syndrome', Bcc infections are also associated with increased morbidity and mortality (Corey \& Farewell, 1996; Murray et al., 2008). Bcc strains are emerging as nosocomial pathogens in patients without CF, and outbreaks resulting in bacteraemia have been reported (Bressler et al., 2007). Bcc infections are difficult to treat

Abbreviations: Bcc, Burkholderia cepacia complex; CF, cystic fibrosis; $\mathrm{h} \beta \mathrm{D}-1$, human beta defensin-1; HNP-1, human neutrophil peptide-1; SLPI, secretory leukocyte protease inhibitor. due to these species' inherent resistance to antibiotics (Mahenthiralingam et al., 2005; Nair et al., 2004, 2005).

B. cenocepacia and Burkholderia multivorans are the most frequently isolated Bcc species from CF patients (Govan et al., 2007; LiPuma, 2005; Reik et al., 2005). B. cenocepacia accounts for most transmissible strains, although transmissible strains of B. multivorans and Burkholderia dolosa have also been reported in some CF centres (Biddick et al., 2003; LiPuma et al., 2001; McDowell et al., 2004; Speert et al., 2002). CF patients infected with B. cenocepacia have a much lower success rate after lung transplantation compared to $\mathrm{CF}$ patients infected with other Bcc species or not infected with Bcc (Alexander et al., 2008; Murray et al., 2008).

Several potential virulence factors have been characterized and implicated in the pathogenesis of Bcc lung infections (Mahenthiralingam et al., 2005; Vial et al., 2007). B. cenocepacia and at least four other Bcc species contain two distinct zinc metalloproteases, designated ZmpA and ZmpB. The zmpA and $z m p B$ genes are always present in the same Bcc species but are not genetically linked. Species that lack both these genes have no detectable protease activity on skim milk agar, suggesting that these are the only extracellular proteases with casein activity (Corbett et al., 2003; Gingues et al., 2005; Kooi et al., 2006). Both $\mathrm{ZmpA}$ and $\mathrm{ZmpB}$ have pre-proenzyme structures and are autoproteolytically converted into a mature protease and a propeptide (Kooi et al., 2005, 2006). Recombinant forms of both proteases have been expressed and purified from 
Escherichia coli (Kooi et al., 2005, 2006). Although ZmpA and $\mathrm{ZmpB}$ are functionally similar, they share little sequence similarity with the exception of the conserved active site and zinc ligand motifs characteristic of zinc metalloproteases.

ZmpA and ZmpB have broad-spectrum activity and degrade substrates involved in tissue integrity or host defence, including type IV collagen, fibronectin, neutrophil $\alpha_{1-p r o t e i n a s e}$ inhibitor and $\alpha_{2}$-macroglobulin. ZmpA cleaves gamma interferon and $\mathrm{ZmpB}$ degrades transferrin, lactoferrin and human immunoglobulins $\operatorname{IgA}$, IgG and IgM. The specificity of each enzyme is clearly different in that ZmpA generally cleaves its substrates into two to three peptides whereas $\mathrm{ZmpB}$ cleaves substrates into a large number of small peptides (Kooi et al., 2005, 2006). We have shown that both proteases contribute to virulence in a chronic respiratory infection model. A mutation in either gene in B. cenocepacia strain K56-2 results in decreased lung pathology compared to the parent strain; however, a mutation in $z m p A$ also results in reduced ability to survive in vivo since $z m p A$ mutants are cleared from the lungs whereas the parent strain maintains a persistent chronic infection (Corbett et al., 2003; Kooi et al., 2006).

Burkholderia spp. are highly resistant to antimicrobial cationic peptides that typically kill bacteria by membrane disruption. LPS structure has been shown to play an important role in resistance to polymyxins and other peptides in both B. cenocepacia (Loutet et al., 2006) and Burkholderia pseudomallei (Burtnick \& Woods, 1999). Other mechanisms of bacterial resistance to antimicrobial peptides have been described, including alteration of surface charges, changes in membrane proteins, efflux pumps/transporters and proteolytic enzymes (Brogden, 2005; Hiemstra et al., 2004; Potempa et al., 2009; Yount \& Yeaman, 2005). It is likely that Burkholderia spp. employ multiple mechanisms to achieve their high degree of resistance to antimicrobial peptides. Since ZmpA and ZmpB are both broad-spectrum proteases, it is possible that one or both may be able to inactivate antimicrobial peptides by proteolytic cleavage. In this study, we determined the ability of purified ZmpA and ZmpB to degrade representative $\alpha$ - and $\beta$-defensins, LL-37, elafin and secretory leukocyte protease inhibitor (SLPI). We also compared the resistance of $B$. cenocepacia wild-type and a $z m p A z m p B$ mutant to antimicrobial peptides to determine if the absence of $\mathrm{ZmpA}$ and $\mathrm{ZmpB}$ renders B. cenocepacia more sensitive to microbial killing.

\section{METHODS}

Strains. B. cenocepacia $\mathrm{K} 56-2$ is a $\mathrm{CF}$ respiratory isolate (Mahenthiralingam et al., 2000). K56-2 zmpA zmpB has been previously described (Kooi et al., 2006). This mutant has a trimethoprim resistance cassette inserted into the BsiWI site of $z m p A$ and a tetracycline resistance cassette inserted into the remaining SalI site in $z m p B$ after deletion of the internal $1.4 \mathrm{~kb}$ Sall fragment. K56-2 zmpA zmpB was grown in medium supplemented with $200 \mu \mathrm{g}$ tetracycline $(\mathrm{Tc}) \mathrm{ml}^{-1}$ and $100 \mu \mathrm{g}$ trimethoprim $(\mathrm{Tp}) \mathrm{ml}^{-1}$.
Substrates. Human neutrophil peptide-1 (HNP-1), human beta defensin-1 (h $\beta \mathrm{D}-1)$ and LL-37 were obtained from AnaSpec. Recombinant $\mathrm{h} \beta \mathrm{D}-1$ was obtained from Cell Sciences. Recombinant human SLPI was obtained from R\&D Systems. Protamine sulfate salt from salmon, cathepsin G from human sputum, elastase from human leukocytes (HLE), lysozyme from human neutrophils, recombinant human elafin and succinyl-Ala-Ala-Ala-p-nitroanilide were purchased from Sigma.

Protease digestions. Recombinant $\mathrm{ZmpA}$ and $\mathrm{ZmpB}$ were purified as previously described (Kooi et al., 2005, 2006). Using hide powder azure as a substrate (Rinderknecht et al., 1968), one unit of activity was defined as the amount of protease that produced a change of 0.1 $A_{595}$ per hour at $37{ }^{\circ} \mathrm{C}$. Protease digestions of antimicrobial peptides were performed essentially as previously described (Kooi et al., 2005, 2006). One microgram of peptide was incubated at $37{ }^{\circ} \mathrm{C}$ with $2 \mathrm{U}$ $\mathrm{ZmpB}$ in $25 \mathrm{mM}$ MES pH 5.6, $1 \mathrm{mM} \mathrm{CaCl}_{2}$ or $\mathrm{ZmpA}$ in $10 \mathrm{mM}$ Tris $\mathrm{pH} 7.2 \mathrm{in}$ a final volume of $50 \mu \mathrm{l}$ for $16 \mathrm{~h}$ unless otherwise indicated. Recombinant $\mathrm{ZmpB}$, recombinant $\mathrm{ZmpA}$ and substrate-only controls were included. Products of digested peptides were separated by Tricine/SDS-16\% PAGE (Schagger \& von Jagow, 1987) and were visualized by Coomassie blue $\mathrm{R}$ staining.

Antimicrobial peptide killing assays. Liquid protamine killing assays were performed essentially as described previously (Banemann et al., 1998), with minor modifications. Briefly, overnight cultures were grown for $16 \mathrm{~h}$ at $37^{\circ} \mathrm{C}$ in $\mathrm{L}$ broth, subcultured at 100 -fold dilution in $\mathrm{L}$ broth without antibiotics and grown to mid-exponential phase. Dilutions of the cultures were made in L broth or PBS. Serial twofold dilutions of the antimicrobial peptide were performed in water ( $\mathrm{pH}$ 5.0). Fifty microlitres of each peptide dilution was mixed with an equal volume of bacterial suspension $\left(10^{5}\right.$ c.f.u. $\left.\mathrm{ml}^{-1}\right)$. A PBS/bacteria mix was used as a reference control to determine a $100 \%$ survival rate. After $1 \mathrm{~h}$ incubation at $37{ }^{\circ} \mathrm{C}$, serial dilutions of the bacteria/peptide mixture were plated on LB agar plates. Results were recorded as percentage survival. Elafin (Simpson et al., 1999) and $\mathrm{h} \beta \mathrm{D}-1$ (Morrison et al., 1998) killing assays were performed as previously described except the $\mathrm{h} \beta \mathrm{D}-1$ bacteria/peptide mixtures were incubated for $2.5 \mathrm{~h}$.

Inactivation of antimicrobial peptide activity. Protamine $(125 \mu \mathrm{g}$ $\left.\mathrm{ml}^{-1}\right)$ was treated with $\mathrm{ZmpA}(2 \mathrm{U})$ in $10 \mathrm{mM}$ Tris $\mathrm{pH} 7.2$ or $\mathrm{ZmpB}$ $(2 \mathrm{U})$ in $25 \mathrm{mM}$ MES pH 5.6, $1 \mathrm{mM} \mathrm{CaCl}_{2}$ in a final volume of $50 \mu \mathrm{l}$ for $16 \mathrm{~h}$ at $37{ }^{\circ} \mathrm{C}$. Protamine $\left(125 \mu \mathrm{g} \mathrm{ml}^{-1}\right)$-only (no protease) and buffer-only controls were included. After incubation, the samples were serially diluted twofold ( 125 to $0.11 \mu \mathrm{g} \mathrm{m}^{-1}$ ) and $10^{5}$ c.f.u. E. coli $\mathrm{DH} 5 \alpha$ were added, followed by incubation for $1 \mathrm{~h}$ at $37{ }^{\circ} \mathrm{C}$ with shaking. Samples were serially diluted and plated on L-agar plates to obtain surviving bacterial numbers.

Inactivation of elafin anti-protease activity. Recombinant $\mathrm{ZmpA}$ or $\mathrm{ZmpB}(4 \mathrm{U})$ in a final volume of $100 \mu \mathrm{l}$ or buffer controls were incubated with elafin $(5 \mu \mathrm{g})$ for $16 \mathrm{~h}$ at $37{ }^{\circ} \mathrm{C}$. Half of the samples were removed to confirm digestion by Tricine/SDS-PAGE and the other half were retained for elastase inhibition assays based on Cooley et al. (2001) with some modifications. Briefly, serial dilutions of treated elafin were incubated with porcine pancreatic elastase $(1.25 \mu \mathrm{M})$ at final elafin: elastase molar ratios of $1: 4$ to $1: 128$ in PBS, $0.05 \%$ Tween-20. A porcine pancreatic elastase only (no elafin, no protease) reference control was set up in parallel. After $30 \mathrm{~min}$ incubation at $37^{\circ} \mathrm{C}, 77 \mu \mathrm{l}$ of $20 \mathrm{mM}$ Tris/ $\mathrm{HCl}, \mathrm{pH} 7.4,0.5 \mathrm{M} \mathrm{NaCl}$, $0.1 \%$ PEG and $3 \mu \mathrm{l} 50 \mathrm{mM}$ substrate succinyl-Ala-Ala-Ala-pnitroanilide was added. Changes in $A_{415}$ were monitored. The $A_{415}$ of the elastase-only control was set at $100 \%$ and the $\%$ elastase activity of the samples were determined as follows: $\left(A_{415}\right.$ of the sample $/ A_{415}$ of the elastase-only control) $\times 100$. 
Statistical analysis. Statistical analysis was performed using oneway analysis of variance (ANOVA) with Dunnett's multiple comparisons test or Student's $t$-test. A $P$-value less than 0.05 was considered significant.

\section{RESULTS AND DISCUSSION}

\section{Ability of $\mathrm{ZmpA}$ and $\mathrm{ZmpB}$ to use antimicrobial peptides as substrates}

Defensins are important components of lung innate immunity. HNP-1 is expressed predominantly by neutrophils and $\mathrm{h} \beta \mathrm{D}-1$ is constitutively expressed by mucosal epithelial cells (Brogden, 2005; Brown \& Hancock, 2006; Mookherjee \& Hancock, 2007). LL-37 is a cathelicidin expressed by both neutrophils and epithelial cells. To determine if $\mathrm{ZmpA}$ and $\mathrm{ZmpB}$ were able to use these antimicrobial peptides as substrates, recombinant forms of $\mathrm{ZmpA}$ and $\mathrm{ZmpB}$ were incubated with the peptides, after which the incubation mixtures were separated by Tricine/ SDS-PAGE. Neither ZmpB nor ZmpA cleaved HNP-1 (Fig. 1a). Interestingly, ZmpB but not $\mathrm{ZmpA}$ degraded h $\beta$ D-1 (Fig. 1b), and ZmpA but not ZmpB degraded LL-37 (Fig. 1c). Due to the small size of $\mathrm{h} \beta \mathrm{D}-1$ and LL-37 it was not possible to determine by Tricine/SDS-PAGE if these peptides were cleaved more than once by the proteases. Elafin and SLPI are peptides with antimicrobial activity, with the ability to eliminate pulmonary pathogens, as well as inhibitors of neutrophil elastase (Doumas et al., 2005; Hiemstra et al., 2004; Sallenave, 2000). Both ZmpB and ZmpA digested elafin and SLPI (Fig. 1d, e). As with $\mathrm{h} \beta \mathrm{D}-1$ and LL-37, the elafin cleavage products were not visible on the gel. The SLPI cleavage products were, however, clearly resolved by Tricine/SDS-PAGE. The masses of the peptides following incubation with $\mathrm{ZmpA}$ or $\mathrm{ZmpB}$ were different (Fig. 1e). Similar results have been observed with other host protein substrates, confirming that these proteases have different specificities (Kooi et al., 2005, 2006). Protamine is a fish antimicrobial peptide that is similar in size and charge to the defensins. Salmon protamine was digested by both $\mathrm{ZmpB}$ and $\mathrm{ZmpA}$ into different-size fragments (Fig. 1f). Intact protamine was not visible on the gel, possibly due to aggregation, which may have prevented migration into the gel. Lysozyme is a naturally occurring antibacterial protein that is found in saliva, mucus, nasal secretions, serum and the lysosomes of neutrophils and macrophages. Neither ZmpB nor ZmpA was active against human neutrophil lysozyme under the conditions employed (Fig. 1g). The protease digestion assays were performed for $16 \mathrm{~h}$ for maximum sensitivity; however, digestion of LL-37 by ZmpB and ZmpA, respectively, was determined to occur in less than $1 \mathrm{~h}$ (data not shown).

\section{Sensitivity of K56-2 and K56-2 zmpA zmpB to antimicrobial peptides}

Since at least one of the B. cenocepacia zinc metalloproteases could digest $\mathrm{h} \beta \mathrm{D}-1$, LL-37, SLPI, elafin and

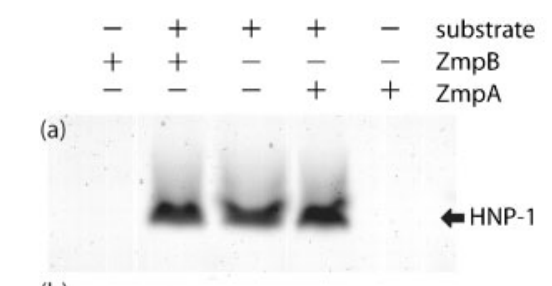

(b)

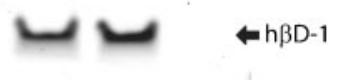

(c)

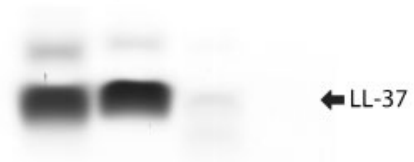

(d)

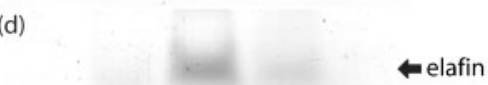

(e)

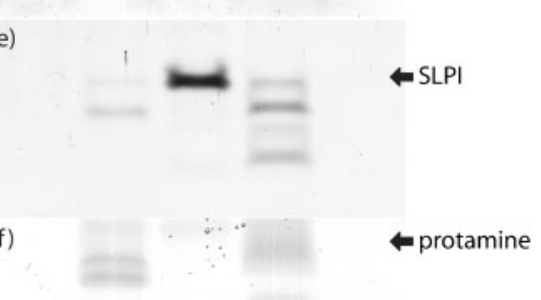

(g)

Fig. 1. Ability of $B$. cenocepacia $Z m p A$ and $Z m p B$ to digest antimicrobial peptides. One microgram of peptide was incubated with $2 \mathrm{U} \mathrm{ZmpA}$ or $\mathrm{ZmpB}$ in a final volume of $50 \mu \mathrm{l}$ and products were separated by Tricine/SDS-16\% PAGE. (a) HNP-1 (3.4 kDa), (b) h $\beta \mathrm{D}-1$ (3.9 kDa), (c) LL-37 (4.5 kDa), (d) elafin (6.0 kDa), (e) SLPI (11.7 kDa), $(\mathrm{f})$ protamine (major component is $5.1 \mathrm{kDa}$ ) and (g) lysozyme (14.7 kDa). Lanes: 1, ZmpB only; 2, ZmpB and antimicrobial peptide; 3, antimicrobial peptide only; 4, ZmpA and antimicrobial peptide; 5, ZmpA only. Gels were scanned with a Umax scanner.

protamine, we next determined if there was a difference in susceptibility to killing by these antimicrobial peptides between a protease-negative mutant (K56-2 zmpA zmpB) and the wild-type strain (K56-2). The zmpA zmpB double mutant was used in most of these assays since one protease with activity against the antimicrobial peptide could render it inactive. K56-2 and $\mathrm{K} 56-2 \quad z m p A \quad z m p B$ were equally resistant to $\mathrm{h} \beta \mathrm{D}-1\left(50 \mu \mathrm{g} \mathrm{ml}^{-1}\right)$ (data not shown). Elafin and SLPI at concentrations up to $2 \mu \mathrm{M}$ had no effect on the viability of either strain (data not shown). Although K56-2 was consistently more resistant to LL-37 than K56-2 $z m p A z m p B$, no significant difference was found (data not shown). A difference was observed in protamine suscept- 
ibility, however, in that K56-2 was significantly more resistant to protamine than was K56-2 zmpA zmpB (Fig. 2) (ANOVA, $P<0.05)$. Similar results were observed with a K56-2 zmpB mutant that still produces active ZmpA.

Since previous studies have demonstrated that Burkholderia species are very resistant to $\beta$-defensins and other antimicrobial peptides (Baird et al., 1999; Burtnick \& Woods, 1999; Loutet et al., 2006; Sahly et al., 2003), it is possible that mutations in $z m p A$ and/or $z m p B$ are insufficient to result in increased susceptibility to the antimicrobial activity of these defensins, due to myriad resistance mechanisms. It is also possible that the cleavage products generated by $\mathrm{ZmpA}$ or $\mathrm{ZmpB}$ retain antimicrobial activity. To test this hypothesis, we attempted to perform killing assays with peptides following incubation with either $\mathrm{ZmpA}$ or $\mathrm{ZmpB}$ using E. coli DH5 $\alpha$ to test for killing. Treatment of protamine with either $Z \mathrm{mpA}$ or ZmpB decreased its ability to kill E. coli (Fig. 3). There was a significant difference between the antimicrobial activity of protamine and that of protamine treated with $\mathrm{ZmpB}$, at concentrations of protamine ranging from 0.9 to $3.6 \mu \mathrm{g}$ $\mathrm{ml}^{-1}$, and protamine treated with $\mathrm{ZmpA}$ at $0.9 \mu \mathrm{g}$ protamine $\mathrm{ml}^{-1}$ (Fig. 3). No differences in killing were observed at concentrations above $3.6 \mu \mathrm{g} \mathrm{ml}^{-1}$ or below $0.9 \mu \mathrm{g} \mathrm{ml}^{-1}$ (data not shown).

Similar experiments were performed with $\mathrm{h} \beta \mathrm{D}-1$ (up to $50 \mu \mathrm{g} \mathrm{ml}^{-1}$ ), elafin (up to $15 \mu \mathrm{g} \mathrm{ml}^{-1}$ ) and SLPI (up to $30 \mu \mathrm{g} \mathrm{ml}^{-1}$ ), but the commercial preparations used of

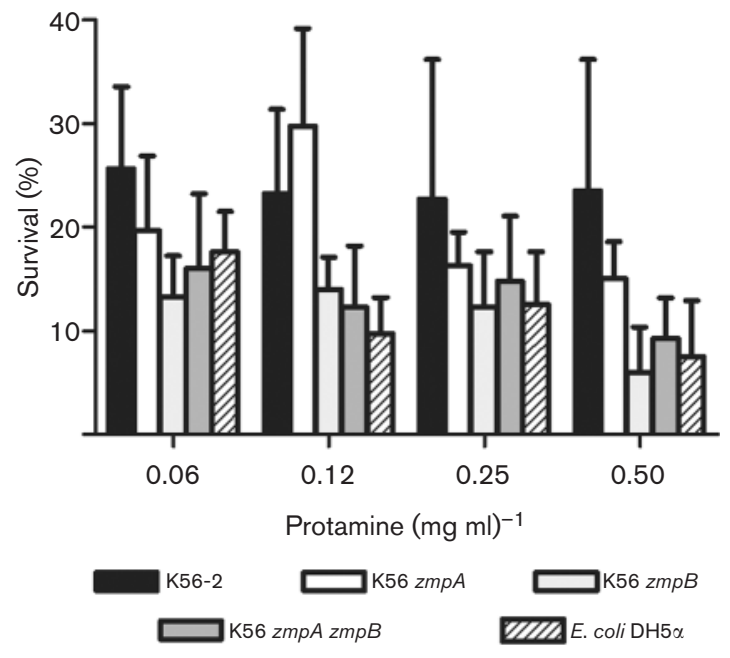

Fig. 2. Protamine liquid killing assay. $\mathrm{K} 56-2, \mathrm{~K} 56-2$ zmpA, K56-2 $z m p B, \mathrm{~K} 56-2$ zmpA zmpB and $E$. coli $\mathrm{DH} 5 \alpha$ were incubated with various concentrations of protamine and the percentage of surviving cells was determined; $100 \%$ survival corresponds to $0 \mathrm{mg}$ protamine $\mathrm{ml}^{-1}$. K56-2 killing by protamine was significantly different from K56-2 zmpB and K56-2 zmpA zmpB $(P<0.01$, ANOVA, Dunnett's multiple comparisons test). The results represent the mean \pm SEM of four independent assays, each performed in duplicate.

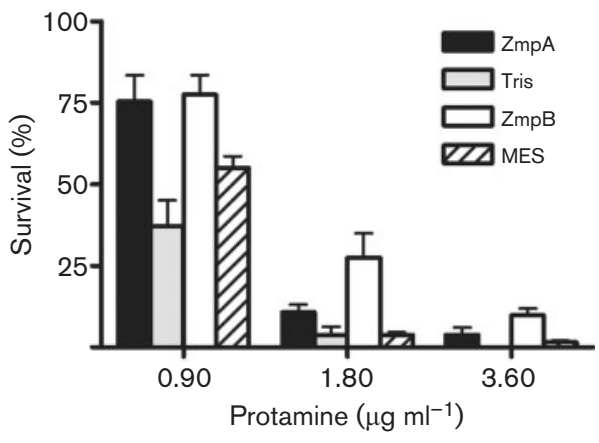

Fig. 3. Ability of $\mathrm{ZmpA}$ and $\mathrm{ZmpB}$ treatment to decrease protamine antimicrobial activity. Protamine was incubated with $2 \mathrm{U} \mathrm{ZmpA}$ or $\mathrm{ZmpB}$, or buffer controls. The residual antimicrobial activity against $E$. coli $\mathrm{DH} 5 \alpha$ was determined using a liquid killing assay. Survival of the control without protamine was set at $100 \%$. ZmpB-treated protamine and buffer-treated protamine were significantly different at $0.9,1.8$ and $3.6 \mu \mathrm{g} \mathrm{ml}^{-1}$, and significantly different between $\mathrm{ZmpA}$-treated protamine and buffer-treated protamine at $0.9 \mu \mathrm{g} \mathrm{ml}^{-1}$ (ANOVA, $P<0.05$ ). Values represent the mean \pm SD of triplicate assays.

these peptides had no antimicrobial activity against E. coli (data not shown). Elafin and $\mathrm{h} \beta \mathrm{D}-1$ have previously been shown to be active against Pseudomonas aeruginosa (Morrison et al., 1998; Simpson et al., 1999). Inactivation of the antimicrobial activity of either elafin or $\mathrm{h} \beta \mathrm{D}-1$ could be relevant in B. cenocepacia and Ps. aeruginosa coinfections. Therefore, we tested the antimicrobial activity of elafin digested with $\mathrm{ZmpA}$ or $\mathrm{ZmpB}$, and $\mathrm{h} \beta \mathrm{D}-1$ digested with $\mathrm{ZmpB}$, against Ps. aeruginosa strain $\mathrm{PAO} 1$ in comparison to the intact peptides. Although recombinant elafin was employed in this assay, we did not observe killing of PAO1 (data not shown). It has previously been demonstrated that the C-terminal domain of elafin contains the antimicrobial activity (Simpson et al., 1999). Since elafin is degraded into very small peptides by $\mathrm{ZmpA}$ and $\mathrm{ZmpB}$, it is unlikely that these peptides would be of sufficient size to retain activity even if a preparation of elafin with antimicrobial activity was used in the assay. We were able to demonstrate killing of PAO1 by $\mathrm{h} \beta \mathrm{D}-1$; however, no difference in killing was observed between intact peptide and that previously incubated with $\mathrm{ZmpB}$ at the $50 \mu \mathrm{g} \mathrm{ml}^{-1}$ concentration tested (data not shown). These data suggest that the proteolytic fragments generated by $\mathrm{ZmpB}$ do retain some antimicrobial activity.

\section{ZmpA and ZmpB inactivate the anti-elastase activity of elafin}

In addition to their antimicrobial properties, elafin and SLPI are inhibitors of host proteases, particularly human neutrophil elastase. To determine if cleavage by ZmpA or $\mathrm{ZmpB}$ reduced the ability of elafin to inhibit elastase, twofold serial dilutions of elafin, pre-incubated with $\mathrm{ZmpA}$ 
or $\mathrm{ZmpB}$, were incubated with porcine pancreatic elastase $(1.25 \mu \mathrm{M})$ at final elafin: elastase molar ratios of $1: 4$ to $1: 128$. Both ZmpA and ZmpB cleavage of elafin significantly decreased its anti-elastase activity (Table 1). Neither ZmpA nor ZmpB had any activity against the elastase substrate, succinyl-Ala-Ala-Ala-p-nitroanilide. Complete elafin cleavage in these assays was confirmed by Tricine/ SDS-PAGE (data not shown). At higher elafin concentrations ( $1: 4$ elafin: elastase molar ratio) elafin inactivation of elastase was observed likely due to the presence of residual uncleaved elafin. The commercial SLPI preparation was found to be inactive since a SLPI : elastase molar ratio of $1: 1$ resulted in no significant decrease in elastase activity (data not shown).

Since inactivation of elafin could alter the protease/ antiprotease balance in the lung, the ability of ZmpA and $\mathrm{ZmpB}$ to cleave neutrophil proteases was also examined. Cathepsin $\mathrm{G}$ is a chymotrypsin-like protease that is a major constituent of human neutrophil granulocytes. Both neutrophil elastase and cathepsin $G$ have been found to be essential for neutrophil killing of bacteria (Reeves et al., 2002). Both cathepsin $G$ and neutrophil elastase are present in the CF lung (Rees \& Brain, 1995) and can cause tissue destruction. Under the digestion conditions employed, neither $\mathrm{ZmpB}$ nor $\mathrm{ZmpA}$ degraded cathepsin $\mathrm{G}$ or neutrophil elastase (data not shown).

\section{SUMMARY AND CONCLUSIONS}

Bacterial proteases are an important mechanism of resistance to host defences and are increasingly being recognized as factors that contribute to antimicrobial peptide resistance. Many proteases have been reported to degrade LL-37, including Proteus mirabilis ZapA (Belas et al., 2004), Staphlylococcus aureus aureolysin (Sieprawska-

Table 1. $\mathrm{ZmpA}$ and $\mathrm{ZmpB}$ inactivation of elafin elastase inhibition activity

\begin{tabular}{|lrcc|}
\hline \multirow{2}{*}{ Elafin $(\boldsymbol{\mu g})$} & \multicolumn{3}{c|}{ Elastase activity $(\%)^{*}$} \\
\cline { 2 - 4 } & Buffer only & ZmpB & ZmpA \\
\hline 0 & $100 \pm 4.2$ & $124.4 \pm 15.6$ & $102.1 \pm 26.4$ \\
0.375 & $0.7 \pm 1.2$ & $4.9 \pm 4.8$ & $10.7 \pm 3.6 \dagger$ \\
0.188 & $3.1 \pm 2.8$ & $6.1 \pm 4.6$ & $14.4 \pm 4.5 \dagger$ \\
0.094 & $4.5 \pm 3.0$ & $10.0 \pm 2.4$ & $20.9 \pm 4.0 \dagger$ \\
0.047 & $9.4 \pm 7.5$ & $11.0 \pm 4.3$ & $29.8 \pm 6.9 \dagger$ \\
0.023 & $13.1 \pm 0.9$ & $48.4 \pm 9.1 \dagger$ & $60.8 \pm 18.9 \dagger$ \\
0.012 & $27.6 \pm 1.3$ & $82.6 \pm 5.8 \dagger$ & $96.3 \pm 12.3 \dagger$ \\
\hline
\end{tabular}

${ }^{*}$ Recombinant $\mathrm{ZmpA}$ or $\mathrm{ZmpB}(4 \mathrm{U} / 50 \mu \mathrm{l})$ or buffer controls were incubated with elafin $(5 \mu \mathrm{g})$ for $16 \mathrm{~h}$ at $37^{\circ} \mathrm{C}$. Treated elafin was incubated with porcine pancreatic elastase $(1.25 \mu \mathrm{M})$ at final elafin: elastase molar ratios of $1: 4$ to $1: 128$.

$\dagger$ Significantly different from no-protease control $(P<0.05$, ANOVA, Dunnett's multiple comparisons test).
Lupa et al., 2004), Ps. aeruginosa LasB, Enterococcus faecalis gelatinase, Streptococcus pyogenes SpeB (Schmidtchen et al., 2002), and a Bacillus anthracis metalloprotease (Thwaite et al., 2006). E. coli OmpT and OmpP proteases degrade protamine (Hwang et al., 2007; Stumpe et al., 1998). Fewer studies have examined the activity of bacterial proteases against other antimicrobial peptides but Pr. mirabilis ZapA has been shown to degrade h $\beta$ D-1 (Belas et al., 2004) and LasB has been shown to cleave SLPI (Sponer et al., 1991). Our studies have shown that at least one of the $B$. cenocepacia $\mathrm{ZmpA}$ and $\mathrm{ZmpB}$ proteases had activity against $\mathrm{h} \beta \mathrm{D}-1$, LL-37, elafin and SLPI. Inactivation of these peptides by ZmpA or $\mathrm{ZmpB}$ could contribute to the inherent resistance of B. cenocepacia.

Proteases have been reported to enhance resistance of other bacterial pathogens to antimicrobial peptides. S. aureus strains that produce aureolysin are more resistant to LL-37 than strains that express no aureolysin activity (Sieprawska-Lupa et al., 2004). Clostridium botulinum protease-positive strains are resistant to protamine whereas protease-negative strains are susceptible (Hansen et al., 2001). We did demonstrate increased protamine susceptibility of a $z m p A z m p B$ mutant compared to the $B$. cenocepacia wild-type strain, suggesting that these proteases could contribute to resistance. The level of susceptibility of the $z m p B$ mutant and the $z m p A z m p B$ mutant was similar to that of the E. coli control, whereas the $z m p A$ mutant was intermediate between the double mutant and the wild-type strain. We also demonstrated that protamine treated with either ZmpB or ZmpA had decreased antimicrobial activity against E. coli.

Unfortunately, commercial preparations of $\mathrm{h} \beta \mathrm{D}-1$, elafin and SLPI did not have antimicrobial activity against $B$. cenocepacia; therefore, we were not able to determine if the $z m p A z m p B$ mutant was more susceptible than the wildtype to these peptides or if cleavage of these peptides with $\mathrm{ZmpA}$ or $\mathrm{ZmpB}$ influenced their antimicrobial activity. Some increased susceptibility of the $z m p A z m p B$ mutant to LL-37 was consistently observed; however, the differences were not statistically significant. It may be difficult to demonstrate large differences in susceptibility in the assay employed since dilution of mid-exponential-phase cultures for the killing assay would result in very low amounts of protease being present.

Although proteolytic enzymes may contribute to the resistance of B. cenocepacia to antimicrobial peptides, it is recognized that other factors, particularly LPS, likely play a greater role. The presence of 4-amino-4-deoxyarabinose (Ara- $4 \mathrm{~N})$ moieties attached to phosphate residues in the lipid A backbone is believed to be involved in the resistance of B. cepacia to antimicrobial peptides (Cox \& Wilkinson, 1991; Shimomura et al., 2003). A complete lipid A-core oligosaccharide was recently shown to be required for resistance to several unrelated antimicrobial peptides and for survival of $B$. cenocepacia $\mathrm{K} 56-2$ in a rat chronic infection model (Loutet et al., 2006). 
Previously we have demonstrated that $\mathrm{ZmpA}$ and $\mathrm{ZmpB}$ cleave neutrophil $\alpha_{1}$-proteinase inhibitor and $\alpha_{2}$-macroglobulin (Kooi et al., 2005, 2006). In this study, we demonstrate that these proteases also have activity against elafin and SLPI. We determined that $\mathrm{ZmpA}$ or $\mathrm{ZmpB}$ cleavage of elafin reduced its anti-elastase inhibitory activity. A great deal of CF lung damage is thought to be due to increased neutropil elastase levels. Inactivation of elastase inhibitors such as $\alpha_{1}$ proteinase inhibitor, SLPI and elafin by ZmpA and ZmpB could disrupt the balance of neutrophil elastase and its inhibitors, contributing to the elevated neutrophil elastase levels in the lung. Since $\mathrm{ZmpA}$ and $\mathrm{ZmpB}$ did not have any direct activity against neutrophil elastase or cathepsin $G$, $\mathrm{ZmpA}$ or $\mathrm{ZmpB}$ produced by B. cenocepacia in the lung would primarily influence the levels of the inhibitors of the neutrophil proteases. Neutrophil elastase and cathepsin G expressed by neutrophils and monocytes are implicated in antimicrobial defence by degrading engulfed micro-organisms inside the neutrophil phagolysosomes. Mice lacking neutrophil elastase (Belaaouaj et al., 1998, 2000) and cathepsin G (Reeves et al., 2002) are deficient in bacterial killing. Elevated levels of neutrophil elastase that occur in CF inflammatory lung disease, however, also have the ability to digest structural elastin, collagen and fibronectin, resulting in extensive tissue damage (Shapiro, 2002). This protease can also degrade the chemokine receptor CXCR1 [interleukin8RA (IL-8RA)] on neutrophils, which in turn can disable the bacterial-killing capacity of these cells (Hartl et al., 2007).

Recently, B. cenocepacia zmpA expression was shown to be upregulated sixfold by growth in medium containing CF sputum, suggesting that ZmpA would likely be present in lungs of CF patients infected with B. cenocepacia (Drevinek et al., 2008). Although $z m p B$ expression was not reported to be elevated in this study, expression analysis was performed on mid-exponential-phase cultures and $z m p B$ is poorly expressed during this phase of growth. Previously, we have reported that both $\mathrm{ZmpA}$ and $\mathrm{ZmpB}$ contribute to the lung pathology observed in a chronic respiratory infection model. It is likely that $\mathrm{ZmpA}$ and $\mathrm{ZmpB}$ enhance the virulence of $B$. cenocepacia by a variety of mechanisms including degradation of antimicrobial peptides, resulting in decreased susceptibility to their killing activity, degradation of neutrophil protease inhibitors, resulting in increased inflammation, as well as direct destruction of tissue and other host defence proteins such as immunoglobulins, transferrin and lactoferrin.

\section{ACKNOWLEDGEMENTS}

This study was supported by operating grant MOP-42510 from the Canadian Institutes of Health Research to P.A.S. D. F. Viteri is acknowledged for excellent technical assistance.

\section{REFERENCES}

Alexander, B. D., Petzold, E. W., Reller, L. B., Palmer, S. M., Davis, R. D., Woods, C. W. \& LiPuma, J. J. (2008). Survival after lung transplantation of cystic fibrosis patients infected with Burkholderia cepacia complex. Am J Transplant 8, 1025-1030.

Baird, R. M., Brown, H., Smith, A. W. \& Watson, M. L. (1999). Burkholderia cepacia is resistant to the antimicrobial activity of airway epithelial cells. Immunopharmacology 44, 267-272.

Banemann, A., Deppisch, H. \& Gross, R. (1998). The lipopolysaccharide of Bordetella bronchiseptica acts as a protective shield against antimicrobial peptides. Infect Immun 66, 5607-5612.

Belaaouaj, A., McCarthy, R., Baumann, M., Gao, Z., Ley, T. J., Abraham, S. N. \& Shapiro, S. D. (1998). Mice lacking neutrophil elastase reveal impaired host defense against gram negative bacterial sepsis. Nat Med 4, 615-618.

Belaaouaj, A., Kim, K. S. \& Shapiro, S. D. (2000). Degradation of outer membrane protein A in Escherichia coli killing by neutrophil elastase. Science 289, 1185-1188.

Belas, R., Manos, J. \& Suvanasuthi, R. (2004). Proteus mirabilis ZapA metalloprotease degrades a broad spectrum of substrates, including antimicrobial peptides. Infect Immun 72, 5159-5167.

Biddick, R., Spilker, T., Martin, A. \& LiPuma, J. J. (2003). Evidence of transmission of Burkholderia cepacia, Burkholderia multivorans and Burkholderia dolosa among persons with cystic fibrosis. FEMS Microbiol Lett 228, 57-62.

Bressler, A. M., Kaye, K. S., LiPuma, J. J., Alexander, B. D., Moore, C. M., Reller, L. B. \& Woods, C. W. (2007). Risk factors for Burkholderia cepacia complex bacteremia among intensive care unit patients without cystic fibrosis: a case-control study. Infect Control Hosp Epidemiol 28, 951-958.

Brogden, K. A. (2005). Antimicrobial peptides: pore formers or metabolic inhibitors in bacteria? Nat Rev Microbiol 3, 238-250.

Brown, K. L. \& Hancock, R. E. (2006). Cationic host defense (antimicrobial) peptides. Curr Opin Immunol 18, 24-30.

Burtnick, M. N. \& Woods, D. E. (1999). Isolation of polymyxin Bsusceptible mutants of Burkholderia pseudomallei and molecular characterization of genetic loci involved in polymyxin B resistance. Antimicrob Agents Chemother 43, 2648-2656.

Chen, J. S., Witzmann, K. A., Spilker, T., Fink, R. J. \& LiPuma, J. J. (2001). Endemicity and inter-city spread of Burkholderia cepacia genomovar III in cystic fibrosis. J Pediatr 139, 643-649.

Coenye, T. \& LiPuma, J. J. (2003). Molecular epidemiology of Burkholderia species. Front Biosci 8, e55-e67.

Coenye, T., Vandamme, P., Govan, J. R. \& LiPuma, J. J. (2001). Taxonomy and identification of the Burkholderia cepacia complex. J Clin Microbiol 39, 3427-3436.

Coenye, T., Vandamme, P., LiPuma, J. J., Govan, J. R. \& Mahenthiralingam, E. (2003). Updated version of the Burkholderia cepacia complex experimental strain panel. J Clin Microbiol 41, 27972798.

Cooley, J., Takayama, T. K., Shapiro, S. D., Schechter, N. M. \& Remold-O'Donnell, E. (2001). The serpin MNEI inhibits elastase-like and chymotrypsin-like serine proteases through efficient reactions at two active sites. Biochemistry 40, 15762-15770.

Corbett, C. R., Burtnick, M. N., Kooi, C., Woods, D. E. \& Sokol, P. A. (2003). An extracellular zinc metalloprotease gene of Burkholderia cepacia. Microbiology 149, 2263-2271.

Corey, M. \& Farewell, V. (1996). Determinants of mortality from cystic fibrosis in Canada, 1970-1989. Am J Epidemiol 143, 1007-1017.

Cox, A. D. \& Wilkinson, S. G. (1991). Ionizing groups in lipopolysaccharides of Pseudomonas cepacia in relation to antibiotic resistance. Mol Microbiol 5, 641-646.

Doumas, S., Kolokotronis, A. \& Stefanopoulos, P. (2005). Antiinflammatory and antimicrobial roles of secretory leukocyte protease inhibitor. Infect Immun 73, 1271-1274. 
Drevinek, P., Holden, M. T., Ge, Z., Jones, A. M., Ketchell, I., Gill, R. T. \& Mahenthiralingam, E. (2008). Gene expression changes linked to antimicrobial resistance, oxidative stress, iron depletion and retained motility are observed when Burkholderia cenocepacia grows in cystic fibrosis sputum. BMC Infect Dis 8, 121.

Gingues, S., Kooi, C., Visser, M. B., Subsin, B. \& Sokol, P. A. (2005). Distribution and expression of the ZmpA metalloprotease in the Burkholderia cepacia complex. J Bacteriol 187, 8247-8255.

Govan, J. R., Brown, P. H., Maddison, J., Doherty, C. J., Nelson, J. W., Dodd, M., Greening, A. P. \& Webb, A. K. (1993). Evidence for transmission of Pseudomonas cepacia by social contact in cystic fibrosis. Lancet 342, 15-19.

Govan, J. R., Brown, A. R. \& Jones, A. M. (2007). Evolving epidemiology of Pseudomonas aeruginosa and the Burkholderia cepacia complex in cystic fibrosis lung infection. Future Microbiol 2, 153-164.

Hansen, L. T., Austin, J. W. \& Gill, T. A. (2001). Antibacterial effect of protamine in combination with EDTA and refrigeration. Int $J$ Food Microbiol 66, 149-161.

Hartl, D., Latzin, P., Hordijk, P., Marcos, V., Rudolph, C., Woischnik, M., Krauss-Etschmann, S., Koller, B., Reinhardt, D. \& other authors (2007). Cleavage of CXCR1 on neutrophils disables bacterial killing in cystic fibrosis lung disease. Nat Med 13, 1423-1430.

Hiemstra, P. S., Fernie-King, B. A., McMichael, J., Lachmann, P. J. \& Sallenave, J. M. (2004). Antimicrobial peptides: mediators of innate immunity as templates for the development of novel anti-infective and immune therapeutics. Curr Pharm Des 10, 2891-2905.

Hwang, B. Y., Varadarajan, N., Li, H., Rodriguez, S., Iverson, B. L. \& Georgiou, G. (2007). Substrate specificity of the Escherichia coli outer membrane protease OmpP. J Bacteriol 189, 522-530.

Isles, A., Maclusky, I., Corey, M., Gold, R., Prober, C., Fleming, P. \& Levison, H. (1984). Pseudomonas cepacia infection in cystic fibrosis: an emerging problem. J Pediatr 104, 206-210.

Kooi, C., Corbett, C. R. \& Sokol, P. A. (2005). Functional analysis of the Burkholderia cenocepacia ZmpA metalloprotease. J Bacteriol 187, 4421-4429.

Kooi, C., Subsin, B., Chen, R., Pohorelic, B. \& Sokol, P. A. (2006). Burkholderia cenocepacia $\mathrm{ZmpB}$ is a broad-specificity zinc metalloprotease involved in virulence. Infect Immun 74, 4083-4093.

LiPuma, J. J. (2005). Update on the Burkholderia cepacia complex. Curr Opin Pulm Med 11, 528-533.

LiPuma, J. J., Dasen, S. E., Nielson, D. W., Stern, R. C. \& Stull, T. L. (1990). Person-to-person transmission of Pseudomonas cepacia between patients with cystic fibrosis. Lancet 336, 1094-1096.

LiPuma, J. J., Spilker, T., Gill, L. H., Campbell, P. W., III, Liu, L. \& Mahenthiralingam, E. (2001). Disproportionate distribution of Burkholderia cepacia complex species and transmissibility markers in cystic fibrosis. Am J Respir Crit Care Med 164, 92-96.

Loutet, S. A., Flannagan, R. S., Kooi, C., Sokol, P. A. \& Valvano, M. A. (2006). A complete lipopolysaccharide inner core oligosaccharide is required for resistance of Burkholderia cenocepacia to antimicrobial peptides and bacterial survival in vivo. J Bacteriol 188, 2073-2080.

Mahenthiralingam, E., Coenye, T., Chung, J. W., Speert, D. P., Govan, J. R., Taylor, P. \& Vandamme, P. (2000). Diagnostically and experimentally useful panel of strains from the Burkholderia cepacia complex. J Clin Microbiol 38, 910-913.

Mahenthiralingam, E., Urban, T. A. \& Goldberg, J. B. (2005). The multifarious, multireplicon Burkholderia cepacia complex. Nat Rev Microbiol 3, 144-156.

Mahenthiralingam, E., Baldwin, A. \& Dowson, C. G. (2008). Burkholderia cepacia complex bacteria: opportunistic pathogens with important natural biology. J Appl Microbiol 104, 1539-1551.
McDowell, A., Mahenthiralingam, E., Dunbar, K. E., Moore, J. E., Crowe, M. \& Elborn, J. S. (2004). Epidemiology of Burkholderia cepacia complex species recovered from cystic fibrosis patients: issues related to patient segregation. J Med Microbiol 53, 663-668.

Mookherjee, N. \& Hancock, R. E. (2007). Cationic host defence peptides: innate immune regulatory peptides as a novel approach for treating infections. Cell Mol Life Sci 64, 922-933.

Morrison, G. M., Davidson, D. J., Kilanowski, F. M., Borthwick, D. W., Crook, K., Maxwell, A. I., Govan, J. R. \& Dorin, J. R. (1998). Mouse beta defensin-1 is a functional homolog of human beta defensin-1. Mamm Genome 9, 453-457.

Murray, S., Charbeneau, J., Marshall, B. C. \& LiPuma, J. J. (2008). Impact of Burkholderia infection on lung transplantation in cystic fibrosis. Am J Respir Crit Care Med 178, 363-371.

Nair, B. M., Cheung, K. J., Jr, Griffith, A. \& Burns, J. L. (2004). Salicylate induces an antibiotic efflux pump in Burkholderia cepacia complex genomovar III (B. cenocepacia). J Clin Invest 113, 464-473.

Nair, B. M., Joachimiak, L. A., Chattopadhyay, S., Montano, I. \& Burns, J. L. (2005). Conservation of a novel protein associated with an antibiotic efflux operon in Burkholderia cenocepacia. FEMS Microbiol Lett 245, 337-344.

Potempa, M., Potempa, J., Kantyka, T., Nguyen, K. A., Wawrzonek, K., Manandhar, S. P., Popadiak, K., Riesbeck, K., Eick, S. \& Blom, A. M. (2009). Interpain A, a cysteine proteinase from Prevotella intermedia, inhibits complement by degrading complement factor C3. PLoS Pathog 5, e1000316.

Rees, D. D. \& Brain, J. D. (1995). Effects of cystic fibrosis airway secretions on rat lung: role of neutrophil elastase. Am J Physiol 269, L195-L202.

Reeves, E. P., Lu, H., Jacobs, H. L., Messina, C. G., Bolsover, S., Gabella, G., Potma, E. O., Warley, A., Roes, J. \& Segal, A. W. (2002). Killing activity of neutrophils is mediated through activation of proteases by $\mathrm{K}^{+}$flux. Nature 416, 291-297.

Reik, R., Spilker, T. \& LiPuma, J. J. (2005). Distribution of Burkholderia cepacia complex species among isolates recovered from persons with or without cystic fibrosis. J Clin Microbiol 43, 29262928.

Rinderknecht, H., Geokas, M. C., Silverman, P. \& Haverback, B. J. (1968). A new ultrasensitive method for the determination of proteolytic activity. Clin Chim Acta 21, 197-203.

Sahly, H., Schubert, S., Harder, J., Rautenberg, P., Ullmann, U., Schroder, J. \& Podschun, R. (2003). Burkholderia is highly resistant to human beta-defensin 3. Antimicrob Agents Chemother 47, 17391741.

Sallenave, J. M. (2000). The role of secretory leukocyte proteinase inhibitor and elafin (elastase-specific inhibitor/skin-derived antileukoprotease) as alarm antiproteinases in inflammatory lung disease. Respir Res 1, 87-92.

Schagger, H. \& von Jagow, G. (1987). Tricine-sodium dodecyl sulfate-polyacrylamide gel electrophoresis for the separation of proteins in the range from 1 to $100 \mathrm{kDa}$. Anal Biochem 166, 368-379.

Schmidtchen, A., Frick, I. M., Andersson, E., Tapper, H. \& Bjorck, L. (2002). Proteinases of common pathogenic bacteria degrade and inactivate the antibacterial peptide LL-37. Mol Microbiol 46, 157-168.

Shapiro, S. D. (2002). Neutrophil elastase: path clearer, pathogen killer, or just pathologic? Am J Respir Cell Mol Biol 26, 266-268.

Shimomura, H., Matsuura, M., Saito, S., Hirai, Y., Isshiki, Y. \& Kawahara, K. (2003). Unusual interaction of a lipopolysaccharide isolated from Burkholderia cepacia with polymyxin B. Infect Immun $71,5225-5230$. 
Sieprawska-Lupa, M., Mydel, P., Krawczyk, K., Wójcik, K., Puklo, M., Lupa, B., Suder, P., Silberring, J., Reed, M. \& other authors (2004). Degradation of human antimicrobial peptide LL-37 by Staphylococcus aureus-derived proteinases. Antimicrob Agents Chemother 48, 46734679.

Simpson, A. J., Maxwell, A. I., Govan, J. R., Haslett, C. \& Sallenave, J. M. (1999). Elafin (elastase-specific inhibitor) has anti-microbial activity against gram-positive and gram-negative respiratory pathogens. FEBS Lett 452, 309-313.

Speert, D. P., Henry, D., Vandamme, P., Corey, M. \& Mahenthiralingam, E. (2002). Epidemiology of Burkholderia cepacia complex in patients with cystic fibrosis, Canada. Emerg Infect Dis 8, 181-187.

Sponer, M., Nick, H. P. \& Schnebli, H. P. (1991). Different susceptibility of elastase inhibitors to inactivation by proteinases from Staphylococcus aureus and Pseudomonas aeruginosa. Biol Chem Hoppe Seyler 372, 963-970.

Stumpe, S., Schmid, R., Stephens, D. L., Georgiou, G. \& Bakker, E. P. (1998). Identification of OmpT as the protease that hydrolyzes the antimicrobial peptide protamine before it enters growing cells of Escherichia coli. J Bacteriol 180, 4002-4006.

Thwaite, J. E., Hibbs, S., Titball, R. W. \& Atkins, T. P. (2006). Proteolytic degradation of human antimicrobial peptide LL-37 by Bacillus anthracis may contribute to virulence. Antimicrob Agents Chemother 50, 2316-2322.
Vandamme, P., Holmes, B., Vancanneyt, M., Coenye, T., Hoste, B., Coopman, R., Revets, H., Lauwers, S., Gillis, M. \& other authors (1997). Occurrence of multiple genomovars of Burkholderia cepacia in cystic fibrosis patients and proposal of Burkholderia multivorans sp. nov. Int J Syst Bacteriol 47, 1188-1200.

Vanlaere, E., LiPuma, J. J., Baldwin, A., Henry, D., De Brandt, E., Mahenthiralingam, E., Speert, D., Dowson, C. \& Vandamme, P. (2008). Burkholderia latens sp. nov., Burkholderia diffusa sp. nov., Burkholderia arboris sp. nov., Burkholderia seminalis sp. nov. and Burkholderia metallica sp. nov., novel species within the Burkholderia cepacia complex. Int J Syst Evol Microbiol 58, 1580-1590.

Vanlaere, E., Baldwin, A., Gevers, D., Henry, D, De Brandt, E., LiPuma, J. J., Mahenthiralingam, E., Speert, D. P., Dowson, C. \& Vandamme, P. (2009). Taxon K, a complex within the Burkholderia cepacia complex, comprises at least two novel species, Burkholderia contaminans sp. nov. and Burkholderia lata sp. nov. Int J Syst Evol Microbiol 59, 102-111.

Vial, L., Groleau, M. C., Dekimpe, V. \& Deziel, E. (2007). Burkholderia diversity and versatility: an inventory of the extracellular products. J Microbiol Biotechnol 17, 1407-1429.

Yount, N. Y. \& Yeaman, M. R. (2005). Immunocontinuum: perspectives in antimicrobial peptide mechanisms of action and resistance. Protein Pept Lett 12, 49-67.

Edited by: P. Cornelis 